\title{
Body Fat and Body-Mass Index among a Multiethnic Sample of College-Age Men and Women
}

\author{
Catherine L. Carpenter, Eric Yan, Steve Chen, Kurt Hong, Adam Arechiga, \\ Woo S. Kim, Max Deng, Zhaoping Li, and David Heber \\ Center for Human Nutrition, David Geffen School of Medicine at UCLA, 14-193 Warren Hall, 900 Veteran Avenue, \\ P.O. Box 951742, Los Angeles, CA 90095, USA
}

Correspondence should be addressed to Catherine L. Carpenter; ccarpenter@mednet.ucla.edu

Received 22 November 2012; Revised 8 February 2013; Accepted 22 February 2013

Academic Editor: Analiza M. Silva

Copyright (C) 2013 Catherine L. Carpenter et al. This is an open access article distributed under the Creative Commons Attribution License, which permits unrestricted use, distribution, and reproduction in any medium, provided the original work is properly cited.

\begin{abstract}
Obesity prevalence and average body composition vary by US race and gender. Asian Americans have the lowest prevalence of obesity. Relying on body-mass index (BMI) to estimate obesity prevalence may misclassify subgroups that appear normally weighted but have excess body fat. We evaluated percentage body fat (PBF) and BMI to determine whether BMI reflects PBF consistently across different races. 940 college students were recruited from a local public university over four consecutive years. We measured PBF by bioelectrical impedance analysis (BIA), weight by physicians' scales, and height with stadiometers. Our sample comprised Asians (49\%), Caucasians (23\%), Hispanics (7\%), and Other (21\%). Participants averaged 21.4 years old; BMI was $22.9 \mathrm{~kg} / \mathrm{m}^{2} ; \mathrm{PBF}$ was $24.8 \%$. BMI and PBF varied significantly by race and gender ( $P$ value $=0.002$ and 0.005 for men; 0.0009 and 0.0008 for women). Asian-American women had the lowest BMI $\left(21.5 \mathrm{~kg} / \mathrm{m}^{2}\right)$ but the second highest PBF $(27.8 \%)$. Linear association between BMI and PBF was the weakest $\left(r^{2}=0.09\right)$ among Asian-American women and BMI had the poorest sensitivity $(37 \%)$ to detect PBF. The high PBF with low BMI pattern exhibited by Asian-American women suggests that they could escape detection for obesity-related disease if $\mathrm{BMI}$ is the sole measure that estimates body composition.
\end{abstract}

\section{Introduction}

Body-mass index (BMI), an important indicator of obesity prevalence in large populations, generally reflects degree of fatness among individuals. Body-mass index can however over- or underestimate adiposity depending upon certain circumstances.

Accurate determination of obesity has become exceedingly important because of major health threats posed by excess adiposity. Obesity is associated with increased incidence of cardiovascular disease, diabetes, sleep apnea, degenerative joint disease, and site-specific cancers [1-6]. Moreover, high obesity prevalence could potentially result in shortened life expectancy in the coming years [7] and excess mortality $[8,9]$. Because of the present and future health problems associated with excess adipose tissue, underestimation of obesity, particularly in young adults who might otherwise appear to have normal BMI measures, could lead to false conclusions about body composition and future health status. Underestimation of body fatness in young women for instance may be problematic for future risk of diseases such as breast cancer. Patterns of excess adipose tissue established early in adulthood could promote the occurrence of obesity at menopause, a known risk factor for breast cancer [10-12].

Validation studies have evaluated accuracy of BMI in estimating body fatness, by comparison to more refined measures such as bioelectric impedance analysis (BIA) and dual energy absorptiometry (DXA) [13-21]. Some studies observed low sensitivity of BMI to detect obesity in general $[14,20]$, while others concluded that BMI was most inaccurate in detecting obesity among intermediate ranges of BMI $[13,17,20,21]$. In addition accuracy of BMI to detect body fatness appears to be affected by ethnicity $[15,18-20]$, gender $[17,21]$, and age [13, 19-21].

The prevalence of inactivity has increased among all age groups and is thought to be a major contributor to the 
obesity epidemic [22]. With the rise in sedentary behavior, potentially greater numbers of young and middle aged adults may be susceptible to accumulation of unhealthy amounts of adipose tissue without significant weight change. We undertook a study of young adult college age adults to examine the relationships between percentage body fat and bodymass index among a multiethnic sample living in Southern California.

\section{Materials and Methods}

2.1. Study Population. Serial cross-sectional samples of college-age men and women were recruited during winter quarter of four consecutive years, 2006, 2007, 2008, and 2009 from an undergraduate physiology course at a major public university in Southern California. All 1029 students in the course over the three years were eligible and subsequently enrolled (241 in 2006, 242 in 2007, 239 in 2008, and 307 in 2009) into the study. Data from 940 students with complete covariate information were included.

2.2. Human Research. The study was approved by the Institutional Review Board of the University of California at Los Angeles. We certify that all applicable institutional and governmental regulations concerning the ethical use of human volunteers were followed during this research.

2.3. Demographic Variables. Ethnicity and racial background were self-identified using the following categories: White/Caucasian; Hispanic; Black/African American; Middle Eastern; Indian; Native American; Asian (Eastern); Asian (Southeast); Pacific Islander; and Other. A blank space to write in "Other" was provided, and, additionally, multiple categories could be marked in the event of mixed race or ethnicity. Age was self-reported.

Because of small numbers of individuals in some of the racial/ethnic groups and to increase the power of our stratified analyses we combined race/ethnicity into four groups: Asian, White, Hispanic, and Other. Eastern and Southeastern Asian groups were combined into Asian. Other category consisted of multiple ethnicities, recorded Other, Middle Eastern, Native American, African American, and Pacific Islanders. Self-reported White/Caucasian and Hispanic were retained as singular categories.

2.4. Anthropometric Measurements. Trained clinical technicians conducted all anthropometric measurements. Subjects were weighed while wearing no shoes. Body weight was measured with a physicians' scale. Heights were taken with a stadiometer (Detecto-Medic; Detecto-Scales; Brooklyn, NY).

Bioelectrical impedance analysis (BIA), used to estimate percent body fat $(\mathrm{PBF})$ and fat and fat free mass, was conducted with a quadripolar BIA device (310e Bioimpedance analyzer; Biodynamics, Inc., Seattle, WA). Fat-free mass and fat mass are estimated with a regression equation based on data obtained through comparison with bioimpedance estimates with hydrodensitometry (Biodynamics, Inc., Seattle, WA). The equation used by the present study, and also utilized in our earlier study [13], estimates FFM $=\left(\mathrm{a} \times \mathrm{Ht}^{2}\right)+$ $(\mathrm{b} \times \mathrm{Wt})+(\mathrm{c} \times \mathrm{A})+(\mathrm{d} \times R)+\mathrm{e}$, where FFM is fat-free mass, Ht is height $(\mathrm{cm}), \mathrm{Wt}$ is weight $(\mathrm{kg}), \mathrm{A}$ is age (years), and $R$ is impedance $(\Omega)$. The constants, a through e, are proprietary information of Biodynamics, Inc. We utilized the model for estimation of FFM for our entire study population. We constructed categories of body-mass index using the WHO International Criteria for all populations $\left(<18.5 \mathrm{~kg} / \mathrm{m}^{2}\right.$; $\left.18.5-24.9 \mathrm{~kg} / \mathrm{m}^{2} ; 25-29.9 \mathrm{~kg} / \mathrm{m}^{2} ;>30 \mathrm{~kg} / \mathrm{m}^{2}\right)$ [23], and the WHO criteria for Asian populations with suggested public health action $\left(<23 \mathrm{~kg} / \mathrm{m}^{2} ; 24-27.5 \mathrm{~kg} / \mathrm{m}^{2} ; 27.6-32.49 \mathrm{~kg} / \mathrm{m}^{2}\right.$; $\geq 32.5 \mathrm{~kg} / \mathrm{m}^{2}$ ) [24]. Since there are no accepted cutpoints for percentage body fat [25], we utilized the PBF cutpoints defined in Okorodudu et al., 2010, a diagnostic performance meta-analysis of BMI in relationship with percentage of body fat [26].

2.5. Statistical Analysis. Analysis of variance was used to evaluate differences in anthropometric variable means according to race and gender. We further analyzed associations between $\mathrm{BMI}$ and PBF by constructing multiple linear regression models adjusting for gender and ethnicity and linear regression models of BMI and PBF according to whether Asian or Caucasian separately for males and females. We plotted scatter distributions of BMI and PBF for Asian and Caucasian males and females.

To provide estimates of sensitivity and specificity of BMI to predict $\mathrm{PBF}$, we evaluated distributions of gender and ethnic subgroups according to BMI and PBF. If we consider PBF measured by BIA as the gold standard, we computed sensitivity as the proportion of participants classified as obese by BMI $\left(\geq 30.0 \mathrm{~kg} / \mathrm{m}^{2}\right)$ and PBF $(\geq 25.0 \%$ for men and $\geq 30.0 \%$ for women) divided by the total classified as obese by PBF. We computed specificity as the proportion of participants classified as nonobese (normal or overweight) by BMI $\left(<30.0 \mathrm{~kg} / \mathrm{m}^{2}\right)$ and nonobese (normal or overweight) by PBF ( $<25.0 \%$ for men and $<30 \%$ for women) divided by the total classified as nonobese by PBF [27]. We restricted our estimation of sensitivity and specificity to Asian-Americans and Whites because the other ethnic groups had insufficient numbers to provide stable estimates.

All data analyses were performed using the Statistical Analysis System Version 9.2 (Statistical Analysis System 2008, Cary, NC, USA). All reported $P$ values assume a two-sided alternative hypothesis. $P$ values less than or equal to 0.05 were considered significant.

\section{Results}

Most study participants (see Table 1) were Asian-American (49\%), with 23\% White, 7\% Hispanic, and 21\% Other. Most were females (60\%). Age distribution was fairly narrow, with subjects averaging 21 years old (standard deviation was 1.6 years). Average body-mass index (BMI) was $23 \mathrm{~kg} / \mathrm{m}^{2}$, weight $65.4 \mathrm{~kg}$ (145 pounds), and height 169 centimeters $(\mathrm{cm})(66$ inches). Total PBF estimated by BIA was $25 \%$. Fat mass averaged 17 kilograms (kg); fat-free mass $49 \mathrm{~kg}$. 
TABLE 1: Characteristics of the study population.

\begin{tabular}{|c|c|c|c|}
\hline Variable & Category & $N$ & Percent \\
\hline \multirow{9}{*}{ Racial composition } & East Asian & 364 & 37.92 \\
\hline & SE Asian & 96 & 10.00 \\
\hline & African American & 11 & 1.15 \\
\hline & Hispanic & 68 & 7.08 \\
\hline & Indian & 51 & 5.31 \\
\hline & Middle Eastern & 86 & 8.96 \\
\hline & Pacific Islander & 27 & 2.81 \\
\hline & White & 216 & 22.50 \\
\hline & Other & 41 & 4.27 \\
\hline \multirow{4}{*}{$\begin{array}{l}\text { Combined racial } \\
\text { groups }\end{array}$} & Asian, no Pac Islander & 475 & 49.48 \\
\hline & White & 216 & 22.50 \\
\hline & Hispanic & 68 & 7.08 \\
\hline & $\begin{array}{l}\text { Other, Inc Pac Isl, } \\
\text { Mixed }\end{array}$ & 201 & 20.94 \\
\hline \multirow{2}{*}{ Gender } & Male & 380 & 39.58 \\
\hline & Female & 580 & 60.42 \\
\hline \multirow{4}{*}{$\begin{array}{l}\text { Body-mass index } \\
\text { (WHO-International) }^{*}\end{array}$} & $<18.5$ & 74 & 7.71 \\
\hline & $18.5-24.9$ & 664 & 69.17 \\
\hline & $25.0-29.9$ & 170 & 17.71 \\
\hline & $30.0+$ & 52 & 5.42 \\
\hline \multirow{4}{*}{$\begin{array}{l}\text { Body mass index } \\
\text { (WHO-Asian }^{\text {populations) }}{ }^{* *}\end{array}$} & $<18.5$ & 74 & 7.71 \\
\hline & $18.5-22.9$ & 481 & 50.10 \\
\hline & $23.0-27.49$ & 296 & 30.83 \\
\hline & $27.5+$ & 109 & 11.35 \\
\hline \multirow{4}{*}{ Percent body fat } & $<20.0$ & 230 & 23.96 \\
\hline & $20.0-24.9$ & 227 & 23.65 \\
\hline & $25.0-29.9$ & 291 & 30.31 \\
\hline & $30.0+$ & 212 & 22.08 \\
\hline \multirow{2}{*}{ Age (years) } & Mean & & 21.40 \\
\hline & S.D. & & 1.64 \\
\hline \multirow{2}{*}{ Body mass index } & Mean & & 22.95 \\
\hline & S.D. & & 3.82 \\
\hline \multirow{2}{*}{ Weight (kg) } & Mean & & 65.37 \\
\hline & S.D. & & 14.74 \\
\hline \multirow{2}{*}{ Height (m) } & Mean & & 1.69 \\
\hline & S.D. & & 0.09 \\
\hline \multirow{2}{*}{ Total percent body fat } & Mean & & 24.82 \\
\hline & S.D. & & 6.94 \\
\hline \multirow{2}{*}{ Fat body mass (kg) } & Mean & & 16.52 \\
\hline & S.D. & & 11.4 \\
\hline \multirow{2}{*}{ Fat-free body mass (kg) } & Mean & & 49.15 \\
\hline & S.D. & & 11.76 \\
\hline
\end{tabular}

Almost all anthropometric measures were significantly different according to race and according to gender and race (see Table 2). Hispanics and men of other ethnicities had the highest BMI, both averaging $26 \mathrm{~kg} / \mathrm{m}^{2}$ and $25 \mathrm{~kg} / \mathrm{m}^{2}$, respectively, while Hispanic females (mean $=30 \%)$, Asian females $($ mean $=28 \%)$, and Other females $($ mean $=29 \%)$ had the highest percentage body fat. Asian-American males $($ mean $=174 \mathrm{~cm})(68$ inches $)$ and Asian-American females $($ mean $=161 \mathrm{~cm})(63$ inches $)$ were the shortest among the racial/ethnic subgroups.

Results from multiple linear regression analyses suggested that $52 \%$ of the variability $\left(r^{2}=0.52\right)$ in PBF was explained by BMI, ethnicity, and sex. We further compared degree of association between BMI and PBF for both AsianAmericans and Whites by constructing separate scatter plots for males and females (see Figures 1 and 2). In addition we computed fit of association between BMI and PBF using linear regression models. Among men, the association between BMI and percent body fat was fairly strong and linear for Asian-Americans $\left(r^{2}=0.47\right)$ and less precisely associated for Whites $\left(r^{2}=0.34\right)$. Among females however the association was weaker, particularly among Asian-Americans $\left(r^{2}=0.09\right)$.

We utilized the WHO International (BMI $\geq 30.0 \mathrm{~kg} / \mathrm{m}^{2}$ ) and the WHO Asian (BMI $\geq 27.5$ ) cutpoints for obesity $[23,24]$ and subclassified according to PBF cutpoints for men $(\geq 25 \%)$ and women $(\geq 30 \%)$ defined in Okorodudu et al. [26] to estimate frequency of individuals who were correctly classified by BMI and individuals who were not (see Table 3). If we consider PBF as a more accurate estimation of obesity, the sensitivity of BMI to predict PBF in Asian-American men was $91 \%$. Among Asian-American women however, the sensitivity was much lower at $37 \%$ (see Table 3). Specificity in Asian-American women was higher at $81 \%$, while the specificity of BMI to predict nonobese PBF was poorer in Asian-American men (63\%). Whites showed a similar pattern to Asian-Americans, although the differences were less striking. The sensitivity of BMI to predict PBF among White men (70\%) was higher than White women (50\%), while the reverse was true for specificity. The specificity of BMI to predict non-obese PBF was higher among White women (98\%) compared to White men (72\%).

\section{Discussion}

Our study was designed to evaluate relationships between percentage body fat and body-mass index among a multiethnic sample of college-age men and women living in Southern California. We were interested in determining the extent to which excess adiposity might be occurring among normal to intermediate ranges of body-mass index and whether these relationships may vary according to gender and ethnicity. We utilized comparative measures between body-mass index and percentage body fat to characterize instances where low degree of association may represent elevated body fat in the context of normal BMI measurements.

We studied college-age young adults because this age group, in particular, may be more likely to have BMI measurements in the normal to intermediate range. The average bodymass index for US men $\left(27 \mathrm{~kg} / \mathrm{m}^{2}\right)$ and women $\left(26.5 \mathrm{~kg} / \mathrm{m}^{2}\right)$ 
TABLE 2: Study population characteristics according to race/ethnicity and according to race/ethnicity and gender.

\begin{tabular}{|c|c|c|c|c|c|c|c|c|c|}
\hline \multirow{2}{*}{ Characteristic } & \multicolumn{2}{|c|}{ Asian } & \multicolumn{2}{|c|}{ White } & \multicolumn{2}{|c|}{ Hispanic } & \multicolumn{2}{|c|}{ Other } & \multirow{2}{*}{$P$ value } \\
\hline & Mean & S.D. & Mean & S.D. & Mean & S.D. & Mean & S.D. & \\
\hline & \multicolumn{9}{|c|}{ Overall study population } \\
\hline Age (years) & 21.16 & 1.31 & 21.66 & 2.14 & 21.93 & 2.12 & 21.52 & 1.45 & 0.0001 \\
\hline Height $(\mathrm{cm})$ & 165.89 & 8.78 & 172.49 & 8.99 & 168.48 & 9.91 & 168.91 & 9.53 & 0.0001 \\
\hline Body weight (kg) & 61.79 & 13.08 & 69.07 & 14.16 & 69.80 & 17.07 & 68.36 & 16.15 & 0.0001 \\
\hline BMI $\left(\mathrm{kg} / \mathrm{m}^{2}\right)$ & 22.31 & 3.37 & 23.09 & 3.60 & 24.32 & 4.70 & 23.84 & 4.40 & 0.0010 \\
\hline Percent body fat & 24.57 & 6.97 & 23.67 & 6.55 & 27.30 & 6.73 & 25.81 & 7.06 & 0.0020 \\
\hline Fat mass $(\mathrm{kg})$ & 15.17 & 5.51 & 16.41 & 6.4 & 19.19 & 7.54 & 17.57 & 6.91 & 0.0600 \\
\hline \multirow[t]{2}{*}{ Fat-free mass $(\mathrm{kg})$} & 46.62 & 10.82 & 53.31 & 10.93 & 50.69 & 12.59 & 50.85 & 12.76 & 0.0001 \\
\hline & \multicolumn{9}{|c|}{ Males } \\
\hline Age (years) & 21.12 & 1.36 & 21.95 & 2.69 & 22.71 & 3.00 & 21.51 & 1.66 & 0.0020 \\
\hline Height (cm) & 174.22 & 6.30 & 179.02 & 2.81 & 177.44 & 7.14 & 176.53 & 7.21 & 0.0001 \\
\hline Body weight (kg) & 72.33 & 13.37 & 78.04 & 11.17 & 82.46 & 15.49 & 78.88 & 13.83 & 0.0001 \\
\hline BMI $\left(\mathrm{kg} / \mathrm{m}^{2}\right)$ & 23.74 & 3.73 & 24.38 & 3.23 & 25.85 & 4.54 & 25.36 & 3.74 & 0.0020 \\
\hline Percent body fat & 18.86 & 7.73 & 19.62 & 5.86 & 22.74 & 6.36 & 21.81 & 5.95 & 0.0005 \\
\hline Fat mass $(\mathrm{kg})$ & 14.26 & 7.40 & 15.74 & 6.28 & 19.38 & 8.37 & 17.30 & 6.96 & 0.0005 \\
\hline \multirow[t]{2}{*}{ Fat-free mass $(\mathrm{kg})$} & 58.03 & 7.49 & 62.30 & 7.58 & 63.30 & 9.30 & 61.60 & 9.37 & 0.0010 \\
\hline & \multicolumn{9}{|c|}{ Females } \\
\hline Age (years) & 21.19 & 1.29 & 21.43 & 1.56 & 21.50 & 1.28 & 21.54 & 1.26 & 0.0600 \\
\hline Height $(\mathrm{cm})$ & 161.24 & 6.15 & 167.36 & 6.71 & 163.58 & 7.49 & 162.59 & 5.92 & 0.0001 \\
\hline Body weight (kg) & 55.92 & 8.41 & 62.02 & 12.16 & 62.90 & 13.68 & 59.65 & 12.32 & 0.0001 \\
\hline BMI $\left(\mathrm{kg} / \mathrm{m}^{2}\right)$ & 21.51 & 2.87 & 22.07 & 3.56 & 23.48 & 4.62 & 22.58 & 4.51 & 0.0009 \\
\hline Percent body fat & 27.75 & 4.71 & 26.85 & 5.17 & 29.78 & 5.58 & 29.12 & 6.15 & 0.0008 \\
\hline Fat mass $(\mathrm{kg})$ & 15.67 & 4.11 & 16.94 & 6.47 & 19.09 & 7.14 & 17.79 & 6.90 & 0.0010 \\
\hline Fat-free mass (kg) & 40.26 & 6.18 & 45.09 & 7.26 & 43.81 & 7.97 & 41.96 & 7.26 & 0.0001 \\
\hline
\end{tabular}

BMI: body-mass index.

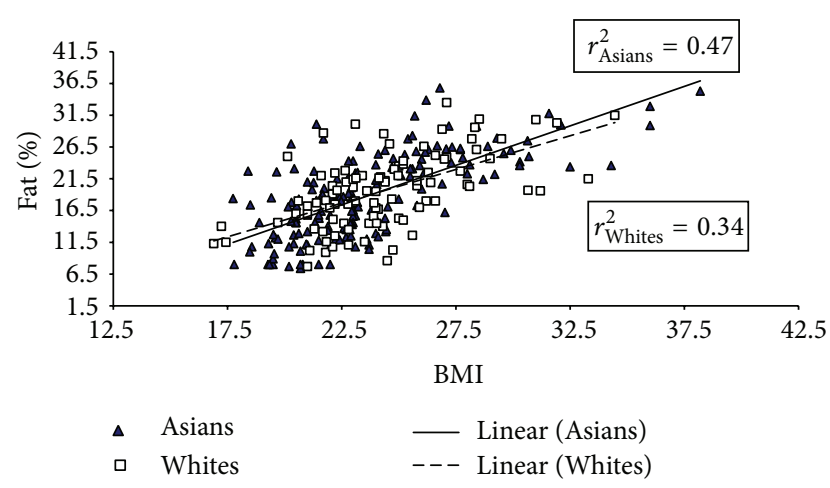

FIGURE 1: Distribution of body-mass index and percentage body fat for males according to race/ethnicity.

between the ages of 20 are 29 is the lowest of all adult age groups younger than age 80 years [28]. The average BMI in our study population was similar to US population norms. Average BMI for males in our study was $24.4 \mathrm{~kg} / \mathrm{m}^{2}$ and females $22.0 \mathrm{~kg} / \mathrm{m}^{2}$.

Estimates for body composition among the college-aged sample were strikingly different for gender and race. Asian men $\left(23.7 \mathrm{~kg} / \mathrm{m}^{2}\right)$ and women $\left(21.5 \mathrm{~kg} / \mathrm{m}^{2}\right)$ had the lowest

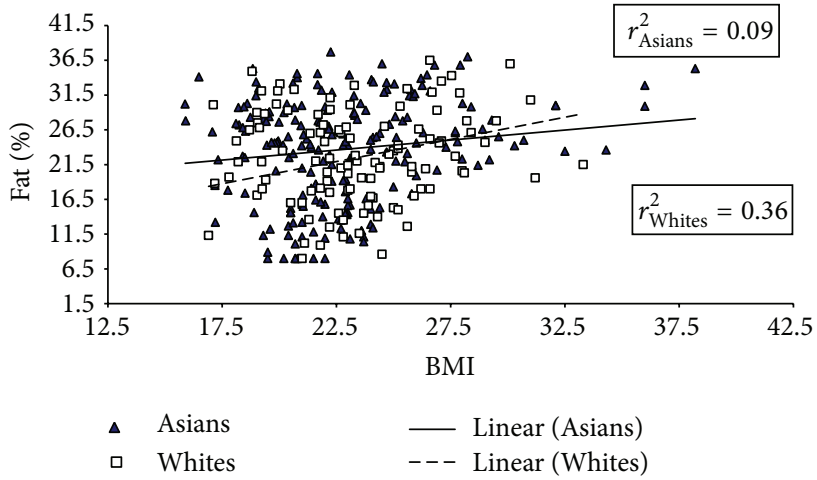

FIGURE 2: Distribution of body-mass index and percentage body fat for females according to race/ethnicity.

mean BMI among the study sample, while Hispanic men $\left(25.9 \mathrm{~kg} / \mathrm{m}^{2}\right)$ and women $\left(23.5 \mathrm{~kg} / \mathrm{m}^{2}\right)$ had the highest mean BMI. Percentage body fat did not follow the same distribution pattern however. While Asian women had the lowest BMI, they did not have the lowest percentage body fat. Asian women had $27.8 \%$ body fat, while Caucasian women, lower than Asian women, had 26.9\%. Hispanic women had the highest percentage body fat $(29.8 \%)$. 
TABLE 3: Classification of obesity for Asian-American and US white college age adults using body-mass index and percentage body fat.

\begin{tabular}{|c|c|c|c|c|c|c|c|c|c|c|c|}
\hline & & \multicolumn{4}{|c|}{$\begin{array}{c}\text { Classification of } \\
\text { obesity in US Whites } \\
\text { BMI }\end{array}$} & & & \multicolumn{4}{|c|}{$\begin{array}{c}\text { Classification of } \\
\text { obesity in US Asians }{ }^{* *} \\
\text { BMI }\end{array}$} \\
\hline & & \multicolumn{2}{|c|}{$<30.0 \mathrm{~kg} / \mathrm{m}^{2}$} & \multicolumn{2}{|c|}{$\geq 30.0 \mathrm{~kg} / \mathrm{m}^{2}$} & & & \multicolumn{2}{|c|}{$<27.5 \mathrm{~kg} / \mathrm{m}^{2}$} & \multicolumn{2}{|c|}{$\geq 27.5 \mathrm{~kg} / \mathrm{m}^{2}$} \\
\hline & & $N$ & $\%$ & $N$ & $\%$ & & & $N$ & $\%$ & $N$ & $\%$ \\
\hline Males & & & & & & Males & & & & & \\
\hline Percentage & $<25 \%$ & 56 & 71.8 & 22 & 28.2 & Percentage & $<25 \%$ & 85 & 63.0 & 50 & 37.0 \\
\hline Body fat & $\geq 25 \%$ & 5 & 29.4 & 12 & 70.6 & Body fat & $\geq 25 \%$ & 3 & 8.6 & 32 & 91.4 \\
\hline Sensitivity & $70.6 \%$ & & & & & Sensitivity & $91.0 \%$ & & & & \\
\hline Specificity & $71.8 \%$ & & & & & Specificity & $63.0 \%$ & & & & \\
\hline Females & & & & & & Females & & & & & \\
\hline Percentage & $<30 \%$ & 89 & 97.8 & 2 & 2.2 & Percentage & $<30 \%$ & 172 & 81.1 & 40 & 18.9 \\
\hline Body fat & $\geq 30 \%$ & 15 & 50.0 & 15 & 50.0 & Body fat & $\geq 30 \%$ & 59 & 63.4 & 34 & 36.6 \\
\hline Sensitivity & $50.0 \%$ & & & & & Sensitivity & $36.6 \%$ & & & & \\
\hline Specificity & $97.8 \%$ & & & & & Specificity & $81.1 \%$ & & & & \\
\hline
\end{tabular}

The correlation between BMI and PBF for the total sample, while moderate, did not indicate variation according to gender and race subgroups. We computed correlation coefficients between BMI and PBF and found that the overall partial correlation between BMI and percentage body fat in our study population, adjusting for race and gender, was 0.63 . Partial correlation for men was 0.63 and women 0.46 , both adjusting for race (data not shown). Our correlation for men was similar to a study using the Third NHANES sample [21]. Their study reported a correlation of 0.69 among men in the 20 to 29 age group [21]. Our reported correlation for women (0.46), on the other hand, was much lower than that reported in NHANES (0.89) [21].

Age, gender, and ethnicity have been found in several studies to affect strength of relationship between BMI and percentage body fat $[13,15,17-21]$. In the population-based NHANES III study, correlations became weaker as age increased [21]. A study of body fatness among 706 African Americans and Caucasian men and women in New York City found that older subjects had higher percentage body fat with similar BMI measurements compared to younger subjects from both racial and gender subgroups [29]. In a recent multiethnic population survey from NHANES 19992004 of BMI and other anthropometric measures, agreement of BMI with percentage body fat varied significantly by race-ethnicity categories [25]. The present study population consisted of young college-age adults with mean and median ages of 21.5 and 21.0, respectively, suggesting that based on previous studies, we ought to be observing stronger agreement between BMI and percentage body fat.

Gender also affects the degree to which BMI predicts body fat $[13,17,21,25,29]$. Females have higher percentages of body fat compared to males of all ages and ethnic groups $[21,25]$, and, for an equivalent BMI, women have significantly greater amount of total body fat than men throughout the entire adult life span [21]. Among all four ethnic subgroups in the present study, females averaged a higher percentage body fat, but lower BMI than males. In all ethnic groups except Whites, females had weaker associations between percentage body fat and BMI than males.

The relationship between PBF and BMI has been shown to differ according to ethnic origin [30]. A meta-analysis concluded that for the same PBF, African Americans and Polynesians have higher BMI compared to Caucasians. In contrast, Chinese, Ethiopians, and Thai BMI measurements are lower than Caucasians [31]. Other studies of Asians have shown that Taiwanese subjects had a relatively lower BMI but higher PBF than Caucasians [18]. Similarly, Indonesians had higher PBF but lower BMI compared to Dutch Caucasians [32], and Japanese young men living in Japan and Australia had greater body fat distribution but lower BMI compared to Australian Caucasians [19]. In our multiethnic sample of young adults, the linear association between BMI and PBF was stronger for Asian men $\left(r^{2}=0.47\right)$ than for Caucasian men $\left(r^{2}=0.34\right)$, while the reverse was true for women. The association between BMI and PBF was the weakest for Asian women $\left(r^{2}=0.09\right)$ compared to Caucasian women $\left(r^{2}=0.36\right)$.

High percentage of body fat occurring at lower BMIs has also been observed among younger Japanese in a multinational study of Japanese, Caucasians, and African Americans conducted in Japan, the United Kingdom, and the United States [33]. The study used DXA, underwater weighing, and $\mathrm{BMI}$, to develop prediction formulas that estimated PBF using a four-compartment model. According to their prediction model, Asians had a significantly higher percentage body fat for any given BMI than Caucasians and African Americans [33].

The low degree of association between BMI and PBF that we observed for young Asian-American women in particular may signal a present and future risk for obesityrelated disease. BMI was a poor predictor of PBF in AsianAmerican women reflected by a low sensitivity (37\%). The low sensitivity and weak association suggest that use of 
BMI to estimate adiposity may be especially inaccurate in Asian-American women. In a comparative study of body composition in Asian and Caucasian young adult females, results showed a similar PBF (31\%) for Taiwanese women aged 20 to 29 , with a similar BMI $\left(23.7 \mathrm{~kg} / \mathrm{m}^{2}\right)$ that we observed [18]. In a comparative study of prepubertal children from China and New York City, similar correlation patterns were observed with Chinese girls having the highest PBF and lowest BMI compared to girls of other geographic and racial origins [34]. In a large cross-sectional study of adiposity from a medical practice in Manhattan, BMI misclassified $48 \%$ of women when DXA was used to validate BMI [35].

Our reliance on BIA to estimate PBF measurement may have contributed to potential inaccuracies in our data. A validation study of body fat estimation by BIA compared to DXA conducted among multiethnic women showed that underestimation of lean body-mass was affected by whether being Caucasian or African American [15], although their study was conducted among overweight to obese women, and whether the same underestimation would occur in a younger normal weighted population with a different ethnic distribution is unclear. In another validation study conducted among 5 European populations, the bias in BIA measurement compared to DXA was minor, particularly among subjects younger than age 35 [16]. Our PBF estimates measured by BIA for Asian females (27.8\%) and Asian males (18.9\%) are close to the PBF observed among Taiwanese females (30.6\%) and males (22\%) between the ages of 20 and 29 measured by the DXA [18].

\section{Conclusions}

In conclusion we observed striking differences in body composition according to gender and ethnicity among a young adult college-age population. While most males and females of different ethnicities had similar associations between PBF and BMI, Asian-American females represented a special subgroup where BMI did not accurately reflect underlying adiposity. The weight and BMI measurements were representative of normal; however the relative high PBF may put Asian-American females at risk for future obesity-related disease.

\section{Abbreviations \\ PBF: Percent body fat \\ BIA: Bioelectric impedance analyst \\ DXA: Dual energy absorptiometry.}

\section{Conflict of Interests}

The authors have no conflict of interests to report.

\section{Acknowledgments}

The authors greatly appreciate the study subjects for their participation. Funding was provided by NIH P01-CA42710.

\section{References}

[1] K. M. Flegal, M. D. Carroll, B. K. Kit, and C. L. Ogden, "Prevalence of obesity and trends in the distribution of body mass index among US adults, 1999-2010," Journal of the American Medical Association, vol. 307, pp. 491-497, 2012.

[2] H. B. Hubert, M. Feinleib, P. M. McNamara, and W. P. Castelli, "Obesity as an independent risk factor for cardiovascular disease: a 26-year follow-up of participants in the Framingham Heart Study," Circulation, vol. 67, no. 5, pp. 968-977, 1983.

[3] F. B. Hu, J. E. Manson, M. J. Stampfer et al., "Diet, lifestyle, and the risk of type 2 diabetes mellitus in women," The New England Journal of Medicine, vol. 345, no. 11, pp. 790-797, 2001.

[4] P. E. Peppard, T. Young, M. Palta, J. Dempsey, and J. Skatrud, "Longitudinal study of moderate weight change and sleepdisordered breathing," Journal of the American Medical Association, vol. 284, no. 23, pp. 3015-3021, 2000.

[5] C. L. Carpenter and L. Bernstein, "Obesity and cancer risk," in Nutritional Oncology, D. Heber, G. Blackburn, V. L. Go, and J. Milner, Eds., Academic Press, Burlington, Mass, USA, 2nd edition, 2006.

[6] P. Manninen, H. Riihimaki, M. Heliovaara, and P. Makela, "Overweight, gender and knee osteroarthritis," International Journal of Obesity and Related Metabolic Disorders, vol. 20, pp. 595-597, 1996.

[7] S. J. Olshansky, D. J. Passaro, R. C. Hershow et al., "A potential decline in life expectancy in the United States in the 21st century," The New England Journal of Medicine, vol. 352, no. 11, pp. 1138-1145, 2005.

[8] E. E. Calle, C. Rodriguez, K. Walker-Thurmond, and M. J. Thun, "Overweight, obesity, and mortality from cancer in a prospectively studied cohort of U.S. adults," The New England Journal of Medicine, vol. 348, no. 17, pp. 1625-1638, 2003.

[9] K. F. Adams, A. Schatzkin, T. B. Harris et al., "Overweight, obesity, and mortality in a large prospective cohort of persons 50 to 71 years old," The New England Journal of Medicine, vol. 355, no. 8, pp. 763-778, 2006.

[10] T. Key, P. Appleby, I. Barnes, and G. Reeves, "Endogenous sex hormones and breast cancer in postmenopausal women: reanalysis of nine prospective studies," Journal of the National Cancer Institute, vol. 94, no. 8, pp. 606-616, 2002.

[11] C. L. Carpenter, R. K. Ross, A. Paganini-Hill, and L. Bernstein, "Effect of family history, obesity and exercise on breast cancer risk among postmenopausal women," International Journal of Cancer, vol. 106, no. 1, pp. 96-102, 2003.

[12] M. L. Slattery, C. Sweeney, S. Edwards et al., "Body size, weight change, fat distribution and breast cancer risk in Hispanic and non-Hispanic white women," Breast Cancer Research and Treatment, vol. 102, no. 1, pp. 85-101, 2007.

[13] D. Heber, S. Ingles, J. M. Ashley, M. H. Maxwell, R. F. Lyons, and R. M. Elashoff, "Clinical detection of sarcopenic obesity by bioelectrical impedance analysis," American Journal of Clinical Nutrition, vol. 64, supplement 3, pp. 472s-477s, 1996.

[14] F. Curtin, A. Morabia, C. Pichard, and D. O. Slosman, "Body mass index compared to dual-energy x-ray absorptiometry: evidence for a spectrum bias," Journal of Clinical Epidemiology, vol. 50, no. 7, pp. 837-843, 1997.

[15] J. M. Jakicic, R. R. Wing, and W. Lang, "Bioelectrical impedance analysis to assess body composition in obese adult women: the effect of ethnicity," International Journal of Obesity, vol. 22, no. 3, pp. 243-249, 1998. 
[16] P. Deurenberg, A. Andreoli, P. Borg et al., "The validity of predicted body fat percentage from body mass index and from impedance in samples of five European populations," European Journal of Clinical Nutrition, vol. 55, no. 11, pp. 973-979, 2001.

[17] D. C. Frankenfield, W. A. Rowe, R. N. Cooney, J. S. Smith, and D. Becker, "Limits of body mass index to detect obesity and predict body composition," Nutrition, vol. 17, no. 1, pp. 26-30, 2001.

[18] C. J. Chang, C. H. Wu, C. S. Chang et al., "Low body mass index but high percent body fat in Taiwanese subjects: implications of obesity cutoffs," International Journal of Obesity, vol. 27, no. 2, pp. 253-259, 2003.

[19] M. Kagawa, D. Kerr, H. Uchida, and C. W. Binns, "Differences in the relationship between BMI and percentage body fat between Japanese and Australian-Caucasian young men," British Journal of Nutrition, vol. 95, no. 5, pp. 1002-1007, 2006.

[20] E. M. Evans, D. A. Rowe, S. B. Racette, K. M. Ross, and E. McAuley, "Is the current BMI obesity classification appropriate for black and white postmenopausal women?" International Journal of Obesity, vol. 30, no. 5, pp. 837-843, 2006.

[21] A. Romero-Corral, V. K. Somers, J. Sierra-Johnson et al., "Accuracy of body mass index in diagnosing obesity in the adult general population," International Journal of Obesity, vol. 32, no. 6, pp. 959-966, 2008.

[22] P. Barnes, Physical Activity among Adults: United States, 2000 and 2005, National Center for Health Statistics, Hyattsville, Md, USA; Center for Disease Control, Atlanta, Ga, USA, 2007.

[23] WHO Expert Committee on Physical Status, "Physical status: the use and interpretation of anthropometry," WHO Technical Report Series, vol. 854, pp. 1-416, 1995.

[24] WHO Expert Consultation, "Appropriate body-mass index for Asian populations and its implications for policy and intervention strategies," The Lancet, vol. 363, pp. 157-163, 2004.

[25] K. M. Flegal, J. A. Shepherd, A. C. Looker et al., "Comparisons of percentage body fat, body mass index, waist circumference, and waist-stature ratio in adults," American Journal of Clinical Nutrition, vol. 89, no. 2, pp. 500-508, 2009.

[26] D. O. Okorodudu, M. F. Jumean, A. Romero-Corral, V. K. Somers, P. J. Erwin, and F. Lopez-Jimenez, "Diagnostic performance of body mass index to identify obesity as defined by body adiposity: a systematic review and meta-analysis," International Journal of Obesity, vol. 34, no. 5, pp. 791-799, 2010.

[27] D. G. Altman and J. M. Bland, "Diagnostic tests 1: sensitivity and specificity," British Medical Journal, vol. 308, no. 6943, p. 1552, 1994.

[28] M. A. McDowell, C. D. Fryar, C. L. Ogden, and K. M. Flegal, "Anthropometric reference data for children and adults: U.S. population, 2003-2006," National Health Statistics Reports, vol. 101, pp. 1-45, U.S. Department of Health and Human Services, Centers for Disease Control and Prevention. National Center for Health Statistics, 2008.

[29] D. Gallagher, M. Visser, D. Sepúlveda, R. N. Pierson, T. Harris, and S. B. Heymsfieid, "How useful is body mass index for comparison of body fatness across age, sex, and ethnic groups?" American Journal of Epidemiology, vol. 143, no. 3, pp. 228-239, 1996.

[30] H. C. Lukaski, "Body mass index, bioelectrical impedance, and body composition," Nutrition, vol. 17, no. 1, pp. 55-56, 2001.

[31] P. Deurenberg, M. Yap, and W. A. van Staveren, "Body mass index and percent body fat: a meta analysis among different ethnic groups," International Journal of Obesity, vol. 22, no. 12, pp. 1164-1171, 1998.
[32] S. Gurrici, Y. Hartriyanti, J. G. Hautvast, and P. Deurenberg, "Relationship between body fat and body mass index: differences between Indonesians and Dutch Caucasians," European Journal of Clinical Nutrition, vol. 52, no. 11, pp. 779-783, 1998.

[33] D. Gallagher, S. B. Heymsfield, M. Heo, S. A. Jebb, P. R. Murgatroyd, and Y. Sakamoto, "Healthy percentage body fat ranges: an approach for developing guidelines based on body mass index," American Journal of Clinical Nutrition, vol. 72, no. 3, pp. 694-701, 2000.

[34] K. P. Navder, Q. He, X. Zhang et al., "Relationship between body mass index and adiposity in prepubertal children: ethnic and geographic comparisons between New York City and Jinan City (China)," Journal of Applied Physiology, vol. 107, no. 2, pp. 488493, 2009.

[35] N. R. Shah and E. R. Braverman, "Measuring adiposity in patients: the utility of body mass index (BMI), percent body fat, and leptin," Public Library of Science One, vol. 7, Article ID e33308, 2012. 


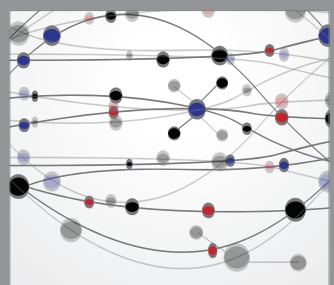

The Scientific World Journal
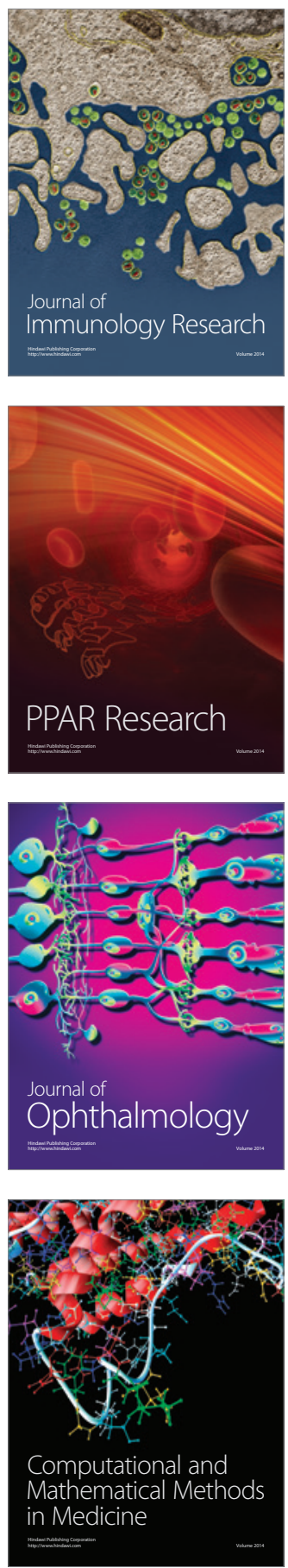

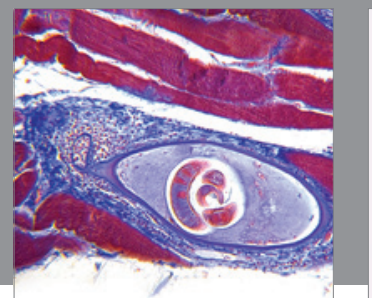

Gastroenterology

Research and Practice
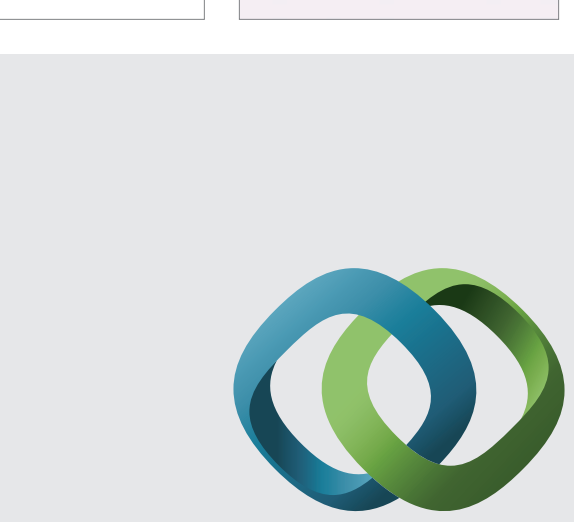

\section{Hindawi}

Submit your manuscripts at

http://www.hindawi.com
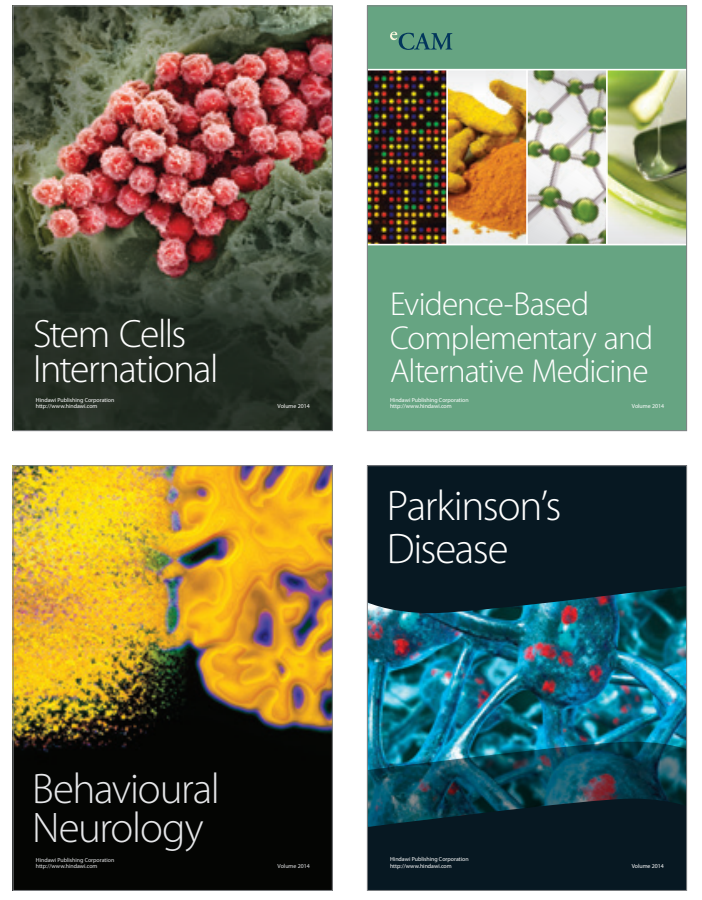
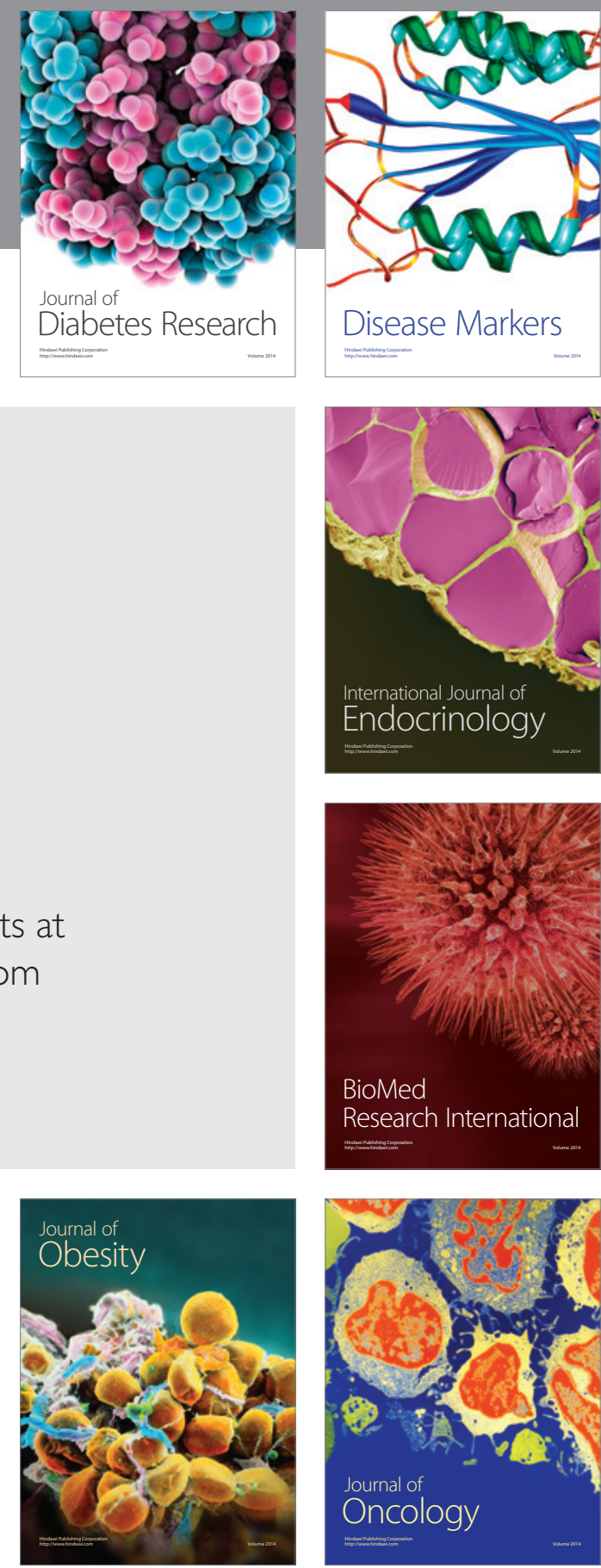

Disease Markers
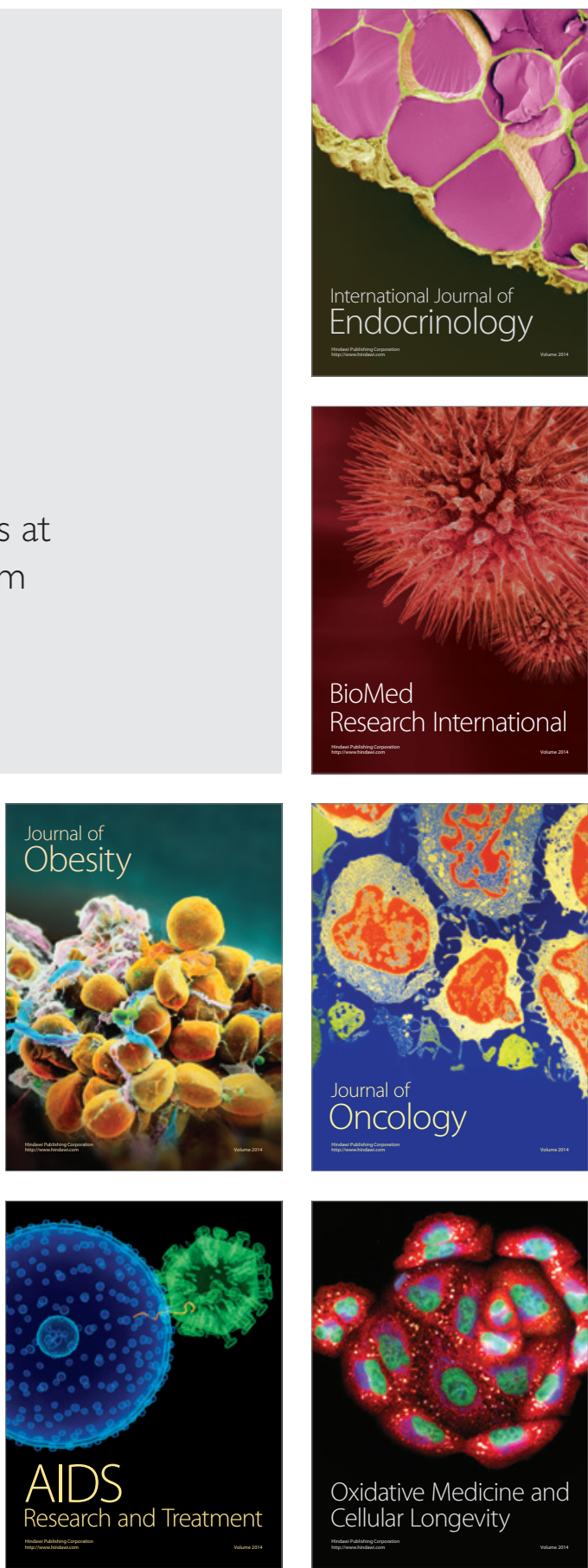